\title{
Practical Singly and Doubly Electrophilic Aminating Agents: A New, More Sustainable Platform for Carbon-Nitrogen Bond-Formation
}

\author{
Padmanabha V. Kattamuri ${ }^{\dagger}$, Jun Yin ${ }^{\dagger}$, Surached Siriwongsup ${ }^{\dagger}$, Doo-Hyun Kwon ${ }^{\ddagger}$, Daniel H.

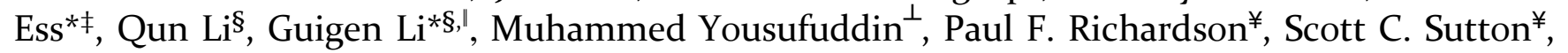 \\ and László Kürti*†
}

${ }^{\dagger}$ Department of Chemistry, Rice University, BioScience Research Collaborative, Houston, TX 77005, USA.
‡Department of Chemistry and Biochemistry, Brigham Young University, Provo, UT 84602, USA.
§Institute of Chemistry \& BioMedical Sciences, Collaborative Innovation Center of Chemistry for Life Sciences, Nan-
jing University, Nanjing, 210093, P. R. China.

'Department of Chemistry and Biochemistry, Texas Tech University, Lubbock, TX 79409, USA.

${ }^{\perp}$ Life and Health Sciences Department, University of North Texas at Dallas, TX 75241, USA.

${ }^{\ddagger}$ Medicinal Sciences, Pfizer Worldwide Research and Development, 10770 Science Center Drive, San Diego, CA 92121

KEYWORDS. Amination, Nitrogen-umpolung, Nitrogen-linchpin, Aminating agents, Arylamine synthesis, Transition metal-free, Catalyst-free

\begin{abstract}
Given the importance of amines in a large number of biologically active natural products, active pharmaceutical ingredients, agrochemicals and functional materials, the development of efficient $\mathrm{C}-\mathrm{N}$ bond-forming methods with wide substrate scope continues to be at the frontiers of research in synthetic organic chemistry. Here, we present a general and fundamentally new synthetic approach for the direct, transition metal-free preparation of symmetrical and unsymmetrical diaryl-, arylalkyl- and dialkylamines that relies on the facile single or double addition of readily available $C$ nucleophiles to the nitrogen atom of bench-stable electrophilic aminating agents. Practical single and double polarity reversal (i.e., umpolung) of the nitrogen atom is achieved using sterically and electronically tunable ketomalonate-derived imines and oximes. Overall, this novel approach represents an operationally simple, scalable and environmentally friendly alternative to transition metal-catalyzed $\mathrm{C}-\mathrm{N}$ cross-coupling methods that are currently used to access structurally diverse secondary amines.
\end{abstract}

\section{Introduction}

Amines and their derivatives are ubiquitous substances since they are present in the overwhelming majority of drug molecules, agrochemicals, functional materials as well as many compounds that are produced by plants and living organisms (i.e., natural products). ${ }^{1-3}$ Not surprisingly, organic chemists spend a considerable amount of time devising the synthesis and late-stage functionalization of amines that serve as key chemical building blocks for the preparation of biologically active compounds, especially in medicinal chemistry. ${ }^{4}$ Among these nitrogencontaining compounds, aromatic and heteroaromatic amines appear as core structures in more than one third of drug candidates and they also serve as important radical-trapping antioxidants utilized in a wide range of industries. The majority of currently utilized methods for the preparation of diaryl- and arylalkyl-amines fall into the following seven broad categories: (a) palladium- or copper-promoted/catalyzed cross-coupling of primary aliphatic or aromatic amines with aryl halides or pseudohalides [i.e., Ullmann-Goldberg reaction ${ }^{5}$ and Buchwald-Hartwig coupling ${ }^{6-8}$ ]; (b) cross-coupling of aryl halides and amines utilizing merged $\mathrm{Ni}(\mathrm{II})$ - and photoredox catalysis9; (c) copper-promoted $N$-arylation of primary anilines with boronic acid derivatives [i.e., Chan-Lam coupling] ${ }^{10-11}$; (d) transition metal- or photoredoxcatalyzed, directed ortho- ${ }^{12}$ as well as non-directed $\mathrm{C}-\mathrm{H}$ amination ${ }^{13-14}$ of arenes with amines or their surrogates; (e) transition metal-catalyzed or promoted cross-coupling of organometallic species (e.g., B, Li, Mg, Zn) with activated amines ${ }^{15-16}$; (f) direct addition of organometallic species $^{17-19}$ or radicals ${ }^{20}$ to nitroarenes and more recently (g) transition metal-free, intra-and intermolecular carbon-nitrogen $(\mathrm{C}-\mathrm{N})$ bond-forming approaches. ${ }^{21-22}$

Most of the methods outlined above utilize transition metal catalysts, ligands and/or forcing conditions (elevated temperatures, high pressure, strong oxidants, etc.), which often require the extensive optimization of reaction parameters and ultimately lead to poor overall atom economy, reduced sustainability and limited substrate scope. Therefore, synthesis of (hetero)aromatic diaryland arylalkyl-amines under mild, operationally simple and environmentally friendly conditions (i.e., ambient temperature, absence of excess reagents or transition metal catalysts and additives) would be highly desirable. 


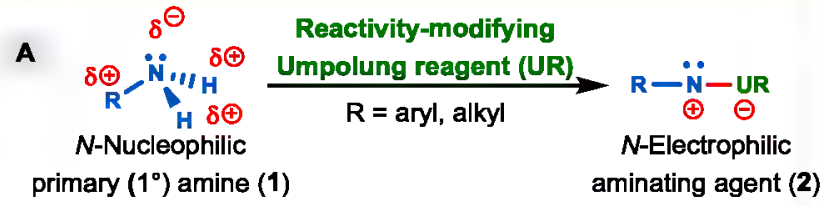

primary $\left(1^{\circ}\right)$ amine (1) aminating agent (2)
E

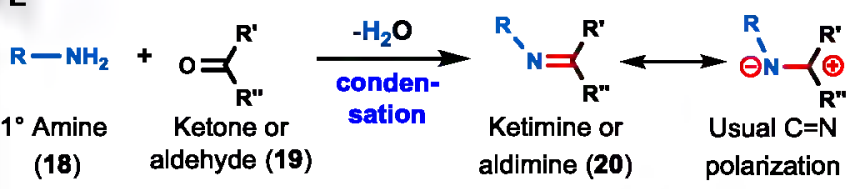

(18) aldehyde (19) polarization

\begin{tabular}{|c|}
\hline Nuc \\
Unprotected \\
secondary $\left(2^{\circ}\right)$ \\
amine (4) \\
\hline
\end{tabular}

$\mathbf{B}$

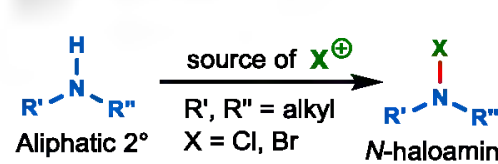
amine (5)
(6)

(heat \& light-sensitive)

C-N C-Nuc-

Removal \& of UR

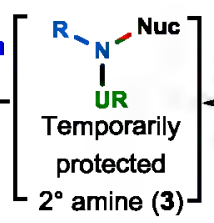

bondformation leophile
(Nuc)

Nuc $=$ aryl- and alkylmetals

$-\mathrm{H}$
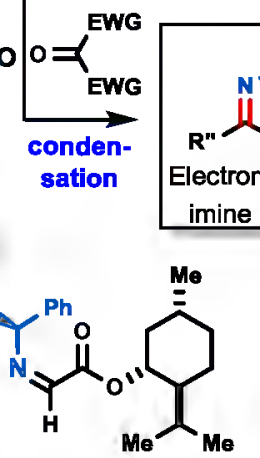

Nuc $R^{1}-N_{8}^{-N}, R^{\prime \prime}$

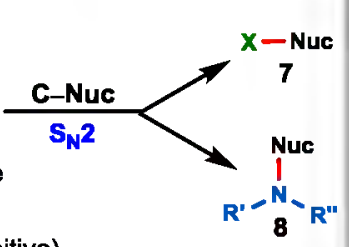

(<smiles></smiles>

-Iminoglyoxylate (22)

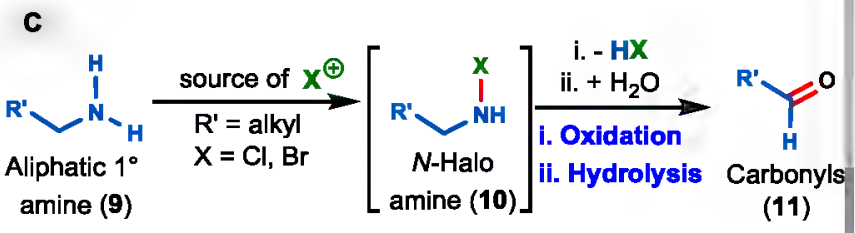

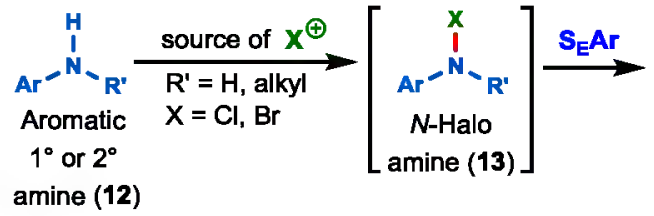

\section{D}

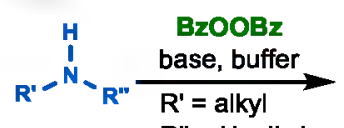
$\mathbf{R}^{\text {OBz }}$

Aliphatic

$1^{\circ}$ or $2^{\circ}$ amine (15)
O-Benzoyl

$\mathrm{R}^{\prime \prime}=\mathrm{H}$, alkyl

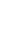

$\mathrm{Bz}=\mathrm{Ph}(\mathrm{C}=\mathrm{O})$ hydroxylamine

(16)

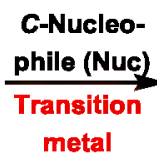

complex

is required

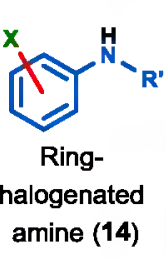
$\underset{\mathrm{Ar}}{\stackrel{\mathrm{N}^{-}-\mathrm{PMP}}{\mathrm{CO}_{2} \mathrm{R}}} \stackrel{\text { i. Alkyl-MgX or }}{\stackrel{\text { (Alkyl })_{2} \mathrm{Zn}}{\longrightarrow}}[$ Electron-poor (E+) iminoester (24)

H<smiles>CCOC(=O)/C(=N\P)OCC</smiles>
N-PMP substituted iminomalonate (27)

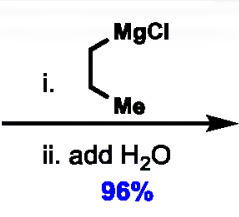

URAPOLUNG OF NITROGEN AFFORDS

N-ELECTROPHILIC IMINES

Figure 1. Current methods for the $N$-umpolung of alkyl and arylamines and design principles of sterically hindered ketomalonate imines and oxime $O$-sulfonates to be used as practical singly and doubly electrophilic aminating agents.

(A) Idealized conversion of a nucleophilic primary amine (1) to a well-defined electrophilic aminating agent (2) that reacts with a $\mathbf{C}$-nucleophile (Nuc) in the absence of any catalyst to form a new $\mathbf{C}-\mathbf{N}$ bond. The initially formed, and temporarily protected, secondary amine (3) yields the free secondary amine (4) upon removal of the reactivity-modifying umpolung reagent (UR). (B) Secondary aliphatic amines undergo facile oxidation with halonium ions to afford the corresponding electrophilic $N$-haloamines (6), which can either transfer the dialkylamino group or the halogen atom to a suitable $C$ nucleophile. (C) The $\mathrm{N}$-halogenation of primary aliphatic (9) or aromatic amines (12) is not practical due to numerous side reactions. (D) A number of primary and secondary amines (15) can be oxidized to the corresponding $O$ benzoylhydroxylamines (16) that almost always require a transition metal to initiate $\mathrm{C}-\mathrm{N}$ bond-formation with $\mathrm{C}-$ nucleophiles. (E) Usual vs unusual $\mathrm{C}=\mathrm{N}$ bond-polarization. (F) Kagan's $\alpha$-iminoester (22) that acts predominantly as an $N-$ electrophile. (G) $N$-p-methoxyphenyl (PMP) substituted $\alpha$-iminoesters (24) serve as precursors for the synthesis of $\alpha$-amino acid derivatives. (H) The only known iminomalonate (27) that undergoes $N$-alkylation with alkylmetal reagents (i.e., no other examples have been reported since). (I) Design principles of practical singly (30) and doubly (31) $N$-electrophilic aminating agents that enable preferential $\mathrm{N}$-versus $\mathrm{C}$-attack by $\mathrm{C}$-nucleophiles. The presence of two bulky electron-withdrawing groups significantly increases the electrophilicity of the nitrogen atom in these reagents compared to iminoesters, thus expands the scope of amination from a few simple alkylmetals to structurally diverse aryl-, heteroaryl- and alkylmetals. 
In fact, from both practical and environmental viewpoints, transition metal-free processes are much preferred, especially in the pharmaceutical industry, where frequent and extensive catalyst/ligand optimizations as well as the removal of undesired metal contamination can be expensive. ${ }^{23-25}$

Based on these facts, there is an urgent need for the development of fundamentally new and general $\mathrm{C}-\mathrm{N}$ bondforming methods that expand the toolbox of synthetic organic chemists and enable the environmentally friendly construction of complex molecular structures using the fewest number of chemical steps and generating the least amount of waste. Therefore, we sought to develop a practical nitrogen umpolung (i.e., polarity reversal) strategy that converts readily available nucleophilic primary $\left(1^{\circ}\right)$ alkyl or arylamines (1) to bench-stable electrophilic nitrogen sources (2) via the use of a reactivity-modifying umpolung reagent (Figure 1, A). Subsequent reaction with a suitable $C$-nucleophile would allow the direct formation of a new $\mathrm{C}-\mathrm{N}$ bond $(\mathbf{2} \rightarrow \mathbf{3})$ under mild reaction conditions and in the absence of transition metal (TM) catalysts. Thus, upon removal/regeneration of the reactivitymodifying umpolung reagent (UR), structurally diverse secondary $\left(2^{\circ}\right)$ diaryl- and arylalkylamines $(4)$ would be obtained in a more sustainable fashion than via currently used methods given that precious metals are not needed, while toxic reagents as well as harsh conditions are avoided.

The conversion of nucleophilic nitrogen-containing compounds to even singly electrophilic nitrogen sources is a challenging task, as the resulting compounds are often heat- and light sensitive due to their inherent high reactivity. ${ }^{26-28}$ For example, secondary aliphatic amines (5; Figure 1, B) can be treated with a suitable halogenating agent (e.g., bleach, NCS, etc.) and the resulting $N$-halo compounds (6) may serve as sources of electrophilic nitrogen.

However, the range of $C$-nucleophiles that can be successfully aminated using this method is fairly limited as a side reaction often occurs in which the halogens get transferred preferentially $(6 \rightarrow 7)$ instead of the desired nitrogen-containing fragment $(\mathbf{6} \rightarrow \mathbf{8})$. Under similar treatment, primary aliphatic amines (9; Figure 1, C) predominantly undergo oxidation and subsequent hydrolysis to form the corresponding carbonyl compounds (11), while primary and secondary aromatic amines (12) suffer ring halogenation $(\mathbf{1 3} \rightarrow \mathbf{1 4}$; i.e., Orton-type rearrangement) due to their electron-rich nature. A limited number of aliphatic primary and secondary amines can be readily oxidized directly with commercially available dibenzoyl peroxide (Luperox ${ }^{\circ}$ ) to furnish the corresponding bench-stable $O$ benzoylhydroxylamine derivatives $(\mathbf{1 5} \rightarrow \mathbf{1 6}$; Figure $1, \mathrm{D})$. Alternatively, simple $N$-alkyl and $N, N$-dialkyl hydroxylamines can be $\mathrm{O}$-acylated in order to obtain aminating agents. ${ }^{29}$ However, these electrophilic nitrogen sources almost always require the use of either an equimolar or substoichiometric amounts of a transition metal complex in order to transfer their aminoalkyl (-NHR) or diaminoalkyl $\left(-\mathrm{NR}_{2}\right)$ groups to a variety of $C$-nucleophiles $(\mathbf{1 6} \rightarrow \mathbf{1 7}){ }^{16,}{ }^{30}$ In addition, many aliphatic amines and most aromatic amines either do not react with dibenzoyl peroxide or complex product mixtures are obtained, thus further limiting the synthetic utility of this electrophilic amination approach.

Given the many, and often severe, limitations of currently utilized nitrogen umpolung methods (Figure 1, B-D), a strong and convincing case could be made for abandoning all approaches that convert $\mathrm{N}\left(\mathrm{sp}^{3}\right)$-hybridized amines to the corresponding $\mathrm{N}\left(\mathrm{sp}^{3}\right)$-hybridized $N$-halogenated or $\mathrm{N}$-oxygenated derivatives. We surmised that conversion of primary amines to $\mathrm{N}\left(\mathrm{sp}^{2}\right)$-hybridized electrophilic imines (Figure 1, E) would eliminate nearly all the limitations of existing $N$-umpolung methods (Figure 1, B-D) and lead to substantially more stable and thus more practical aminating agents. The feasibility of this ambitious new $N$-umpolung approach was contingent on finding suitable activated carbonyl compounds that would allow the facile and direct preparation of $\mathrm{N}$-electrophilic imines from virtually any primary aliphatic or aromatic amine.

A thorough survey of the literature revealed that in 1970 Kagan and Fiaud ${ }^{11}$ were the first to observe that $\alpha$ methylbenzylamine-derived imines of glyoxylate esters (22) preferentially react on the nitrogen atom with simple primary and secondary alkyl Grignard reagents (Figure 1, F). Inspired by this intriguing reversal of normal imine reactivity, during the next 40 years chemists predominantly focused on exploring the reactivity of related electron-poor $\alpha$-iminoesters (Figure $\mathbf{1}, \mathbf{G}$ ) as structurally diverse $\alpha$-amino acid derivatives could be prepared this way. ${ }^{32}$ One of the main drawbacks of the $\alpha$-iminoester system is that the range of suitable $C$-nucleophiles is limited to simple alkylmetals since arylmetals and softer $C$ nucleophiles are apparently not reactive enough to undergo $\mathrm{C}-\mathrm{N}$ bond-formation. Indeed, our own densityfunctional calculations revealed that aryl Grignard reagents have $>30 \mathrm{kcal} / \mathrm{mol}$ barriers for $\mathrm{C}-\mathrm{N}$ bond formation with $\alpha$-iminoesters compared to $<20 \mathrm{kcal} / \mathrm{mol}$ barriers for alkyl Grignard reagents (see SM). In 2001, Shimizu33 et al. briefly explored the reactivity of just one specific electronpoor iminomalonate (27; Figure 1, H) with alkylmagnesium, dialkylzinc and alkylaluminum reagents. However, the conversions were only established by NMR, and the structure and/or purity of the $\mathrm{N}$-alkylated products were not satisfactorily demonstrated due to the absence of any supporting information. Unfortunately, in spite of devoting considerable time and effort, we could not prepare iminomalonate $\mathbf{2 7}$ in a reasonably pure form (our sample had less than $80 \%$ purity), presumably due to its apparent extreme moisture-sensitivity. ${ }^{34}$ Upon reacting 27 with alkylmagnesium halides, we found that substantial amounts of $C$-attack products were formed in addition to the expected $\mathrm{N}$-attack products. It is important to note that no follow-up publications have emerged on the $\mathrm{N}$ alkylation of iminomalonates with $C$-nucleophiles from 
Synthesis of Sterlcally Hindered $\mathbf{N}$-Substltuted ImInomalonates and Evaluatlon of thelr Efflcacy as $\mathbf{N}$-Electrophillc AmInating Agents:

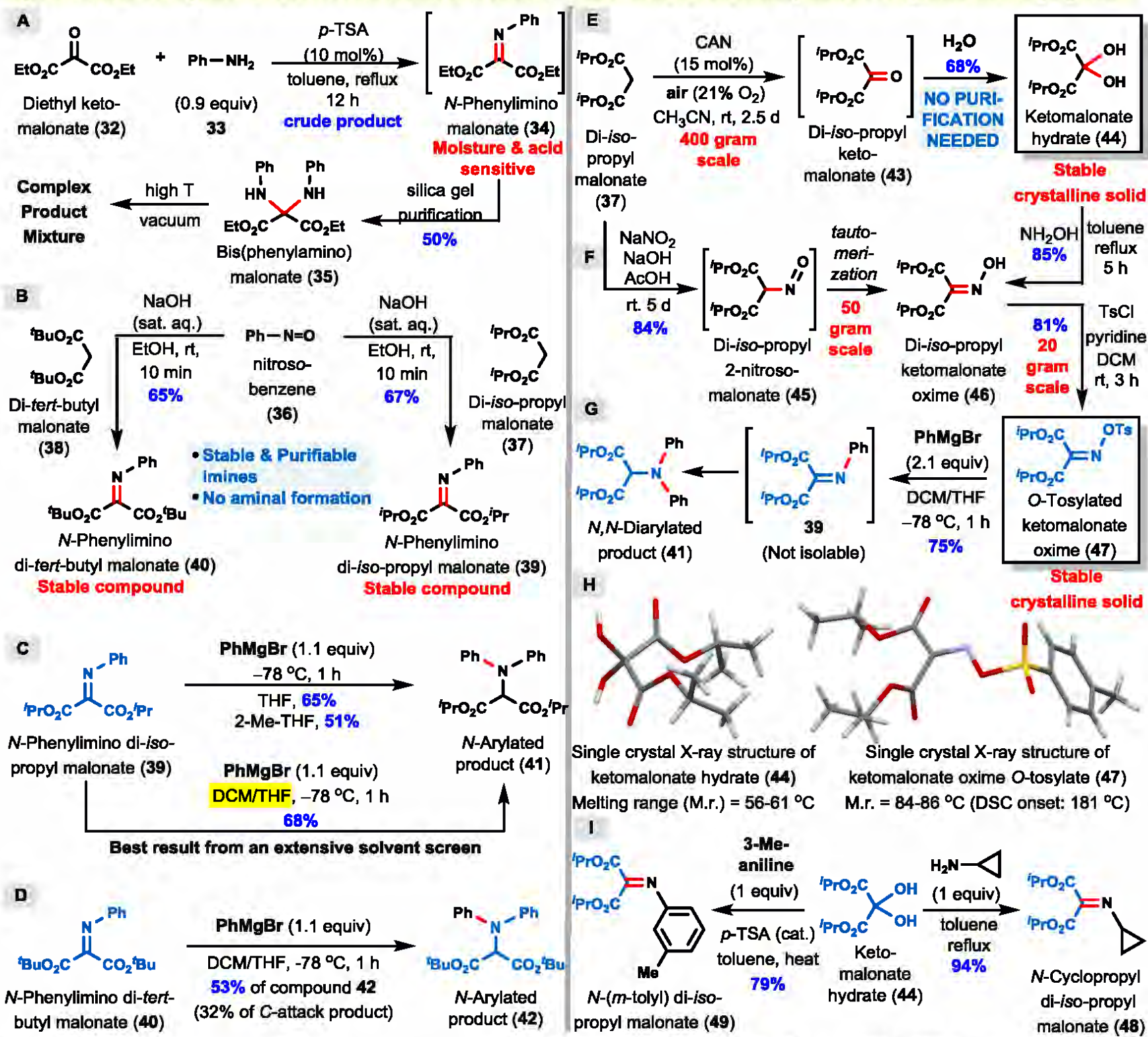

Figure 2. Synthesis of singly and doubly electrophilic $N$-substituted iminomalonates and their reactions with $C$-nucleophiles. (A) When reacted with primary amines, non-sterically hindered ketomalonates, such as 32 , preferentially afford aminals (35) rather than imines (34) under even slightly acidic conditions. (B) Nitrosobenzene (36) reacts rapidly with sterically hindered dialkyl malonates ( 37 \& 38) under basic conditions to afford stable and purifiable $N$-phenyl iminomalonates (39 \& 40). (C \& D) $\mathrm{N}$-Phenyl iminomalonates $39 \& \mathbf{4 0}$ both undergo preferential $\mathrm{N}$-attack by phenylmagnesium bromide. After an extensive solvent screen (see SM), DCM/THF (3:1 to 5:1) was found to be the best solvent mixture for $N$-arylation, presumably because the relatively non-polar DCM keeps the Grignard reagents mostly in their dimeric forms (vide infra). The less hindered di-isopropyl iminomalonate (39) gave better results than the di-tert-butyl derivative (40). (E) Di-i-Pr malonate (37) can be readily oxidized, using catalytic amounts of ceric ammonium nitrate (CAN) and air, on multi-hundred gram scale to the corresponding ketomalonate hydrate (44) that is a stable crystalline solid. (F) When di-iso-propyl malonate (37) is treated under nitrosylation conditions, the corresponding oxime (46) is obtained. This oxime can also be prepared in good yields by heating hydrate 44 with hydroxylamine. (G) O-Tosylated ketomalonate oxime (47), a stable crystalline solid, serves as a doubly electrophilic $\mathrm{N}$ linchpin reagent when reacted with two equivalents of aryl-Grignard reagent to afford the expected $N, N$-diarylated product (41). (H) Single crystal X-ray structures of key reagents 44 and 47; (I) Ketomalonate hydrate 44 undergoes facile condensation with both aliphatic and aromatic amines.

any laboratory (Figure 1, H) since the initial report 33 , therefore we concluded that the shortcomings of this system must have been too numerous to warrant further investigation. Despite our disappointing experience with the suboptimal physical and chemical properties of the $\mathrm{N}$ PMP substituted diethyl iminomalonate (27), calculation of the relative reduction potentials ( $0.3 \mathrm{~V}$ difference) and proton affinities (see SM) indicate that $\mathbf{2 7}$ is significantly 
more electrophilic than the extensively studied $\alpha$ iminoesters (Figure 1, F \& G). Thus, a carefully redesigned iminomalonate system would likely react with a large array of weaker $C$-nucleophiles (e.g., arylmetals, enolates) that do not undergo $\mathrm{C}-\mathrm{N}$ bond formation with $\alpha-$ iminoesters. We also reasoned that judicious structural modification of the iminomalonate system could impart higher stability as well as improved preference for $\mathrm{N}$-versus $C$-attack in its reactions with a wide range of $C$ nucleophiles (Figure 1, I). Specifically, increasing the steric bulk of the ester $\mathrm{R}^{2}$ moiety in ketomalonyl imine 30 from methyl $(\mathrm{Me})$ or ethyl $(\mathrm{Et})$ to iso-propyl ( $i$-Pr) or tertbutyl $(t-\mathrm{Bu})$ would not only result in reduced acid sensitivity but also lead to increased $N$-attack by $C$ nucleophiles due to a significantly more hindered imine $(\mathrm{C}=\mathrm{N})$ carbon atom. In addition, based on our recent experience with substituted hydroxylamine derivatives, the presence of a leaving group on the nitrogen atom (e.g., $\mathrm{O}$ 2,4-dinitrophenyl, O-alkylsulfonyl, $O$-arylsulfonyl or part of an oxaziridine ring) renders it more electrophilic. ${ }^{13}, 16,35-$ 36 Thus, combining two different types of $N$-umpolung approaches (conjugation of the $\mathrm{C}=\mathrm{N}$ bond with two strongly electron-withdrawing groups paired with a good leaving group on the $\mathrm{N}$ atom) in a single reagent could potentially render the nitrogen doubly electrophilic. Given these considerations, $O$-sulfonylated and sterically hindered ketomalonate oximes (31) are expected to be bench-stable doubly $N$-electrophilic (i.e., $N$-linchpin) reagents. Once the single or double $\mathrm{C}-\mathrm{N}$ bond-formation is complete, removal of the malonyl group under mild oxidative conditions and the concomitant regeneration of the reactivity-modifying umpolung reagent (UR) would furnish both symmetrical and unsymmetrical diaryl-, arylalkyl and dialkylamines; therefore this approach could provide a more sustainable alternative to current transition metal-catalyzed $\mathrm{C}-\mathrm{N}$ cross-coupling methods.

\section{Results and Discussion}

In order to fully understand the factors that render diethyl ketomalonate (32) to be an unsuitable reagent for the preparation of iminomalonates, it was condensed with an equimolar amount of aniline (33) under classical Dean-Stark conditions (Figure 2, A). The crude reaction mixture indicated the presence of both the anticipated imine (34) as well as the corresponding aminal (35). Upon silica gel purification of the crude mixture, aminal 35 was obtained exclusively and with high efficiency (i.e., 50\% isolated yield). This result clearly indicated that the imine (34) was prone to undergo both acid-catalyzed hydrolysis as well as aminal formation, presumably because the highly electrophilic imine carbon atom was fully exposed to nucleophilic attack. ${ }^{34}$ Since the sterically more hindered di-iso-propyl and di-tert-butyl ketomalonates were not available commercially, we prepared the corresponding $N$-phenyl iminomalonates $(39 \& 40)$ in good yields by condensing malonate esters 37 and 38 with nitrosobenzene (36) under basic conditions (i.e., Ehrlich-Sachs reaction; Figure 2, B).34 To our delight, iminomalonates 39 and 40 were found to be stable compounds that could be purified by column chromatography without the accompanied formation of aminal derivatives, indicating that the larger alkyl groups (i.e., $i$-Pr and $t$-Bu) on the ester moiety now provide effective shielding to the imine carbon against nucleophilic attack (i.e., hydrolysis).

Exposing iminomalonate 39 to phenylmagnesium bromide in 2-Me-THF or THF yielded the $N$-arylated product (41) in $51 \%$ and $65 \%$ yield, respectively (Figure 2, C). An extensive solvent screen revealed that when the iminomalonate was dissolved in non-polar dichloromethane (DCM) and the ethereal solution of the aryl-Grignard reagent was added at $-78{ }^{\circ} \mathrm{C}$, the yield of the $N$-arylated product 41 was substantially $(51 \%$ or $65 \% \rightarrow 78 \%)$ increased. It is worth noting that the undesired $C$-arylated product was formed in $13 \%$ yield, however it was readily separated from the $N$-arylated product. Consistent with these results, transition-state calculations using $(\mathrm{PhMgBr})_{2}$ with the methyl ester of 39 indicate competitive $\mathrm{N}$-attack and $\mathrm{C}$-attack where subtle changes in solvent will likely have a significant impact on selectivity (see SM). Counterintuitively, both the selectivity and the efficiency of the $N$-attack were lower in the case of di-tertbutyl- $N$-phenyl iminomalonate (40), so the $N$-arylated product (42) was only obtained in 53\% yield (Figure 2, D). ${ }^{37}$ These results prompted us to focus on utilizing the di-isopropylmalonyl group as the key reagent substructure in our studies, which was appreciated given the lower cost of 37 versus $\mathbf{3 8}$.

Accordingly, we developed a multi-hundred gram scale synthesis of diisopropyl keto malonate (43) from commercially available di-isopropyl malonate (37). $3^{8}$ This route is not only operationally simple but also inexpensive, given the use of air as the terminal oxidant (Figure 2, E). It was quickly established that due to the hygroscopic nature of ketomalonate 43, the corresponding hydrate (44) 39 was much easier to handle as it is a stable crystalline solid and obtained directly in pure form after simple filtration (i.e., no column chromatography is needed). The efficient preparation of di-isopropyl ketomalonate oxime (46) was achieved by either subjecting di-isopropyl malonate (37) to nitrosylation conditions ${ }^{40}$ or condensing di-isopropyl ketomalonate hydrate (44) with hydroxylamine (Figure 2, F). Upon treatment with $p$ toluenesulfonyl chloride ( $\mathrm{TsCl})$, oxime 46 was converted to the $O$-tosylated derivative $(47)$, which is a bench-stable white crystalline solid. ${ }^{41}$ As we anticipated, 47 acted as a very efficient doubly electrophilic $N$-linchpin reagent when exposed to two equivalents of phenylmagnesium bromide (Figure 2, G). The $N, N$-diarylated product (41) was formed in $75 \%$ yield while the $C, N$-diarylated product was obtained in $13 \%$ yield (see SM for a brief structure/reactivity study that shows ratios of $N$ - versus $C$ attack products with various aminating agents and $C$ nucleophiles). The presumptive $N$-phenyl iminomalonate (39) intermediate could not be isolated possibly due to its high reactivity towards the Grignard reagent - when 47 was treated with one equivalent of phenylmagnesium bromide, only product $\mathbf{4 1}$ and unreacted 47 were isolated. Structural confirmation for 


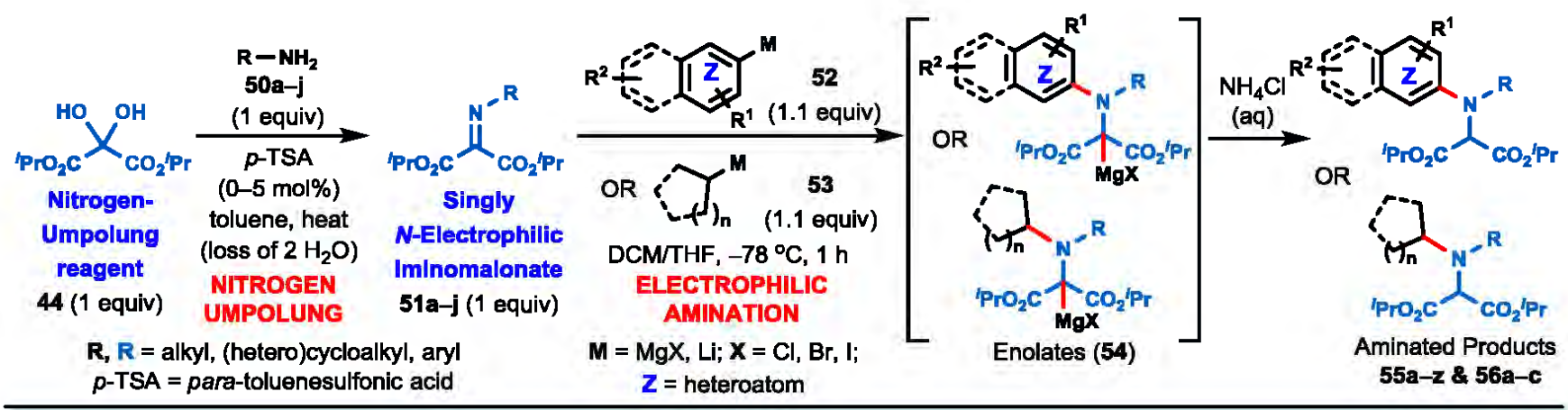

Structure of Symmetrical/Unsymmetrical Dialkyl- and Arylalkylamine Products

(Entry): Compound \#; M (metal), Isolated Yield (\%), Scale (mmol)

Intermolecular Amination of (Cyclo)Alkyl- and (Hetero)Arylmetals With Singly $\mathbf{N}$-Electrophilic Iminomalonates:

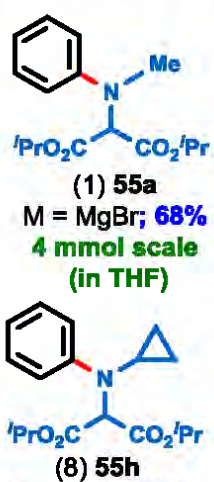

(8) $55 \mathrm{~h}$

$\mathrm{M}=\mathrm{MgBr} ; \mathbf{7 3} \%$

$4 \mathrm{mmol}$ scale<smiles>CCOC(=O)C(C(=O)OCC)N(C)[C@@H](OCC)[N+](=O)[O-]</smiles>

(2) $55 \mathrm{~b}$

$\mathrm{M}=\mathrm{MgCl} ; 80 \%$<smiles>CCCOC(=O)C(C(=O)OCC)N(c1ccc(OC(F)(F)F)cc1)C1CC1</smiles>

(9) $55 \mathrm{i}$

$\mathrm{M}=\mathrm{MgBr} ; 19 \%$<smiles>CCCOC(=O)C(C(=O)OCC)N(CC(F)(F)F)c1ccccc1</smiles>

(3) $55 \mathrm{c}$

$\mathrm{M}=\mathrm{MgBr} ; \mathbf{3 4 \%}$

4 mmol scale<smiles>CCOC(=O)C(C(=O)OCC)N(CC(F)(F)F)c1ccccc1Br</smiles>

(4) $55 d$

$\mathrm{M}=\mathrm{MgCl} ; \mathbf{7 9} \%$

$2 \mathrm{mmol}$ scale<smiles>CCCO[AsH3]</smiles>

(5) $55 \mathrm{e}$

$\mathrm{M}=\mathrm{MgBr} ; \mathbf{5 8} \%$

$3 \mathrm{mmol}$ scale<smiles>CCCOC(=O)C(C(=O)OCC)N(C1CC1)C1CC1</smiles>

(6) $55 f$

$\mathrm{M}=\mathrm{MgBr} ; \mathbf{8 9} \%$<smiles>CCCOC(=O)C(C(=O)OCC)N(C1CCC1)C1CC1</smiles>

(7) $55 \mathrm{~g}$

$\mathrm{M}=\mathrm{MgBr} ; 85 \%$<smiles>CCOC(=O)C(C(=O)OCC)N(CCC[N+](=O)[O-])c1ccc(Cl)cc1</smiles>

(14) $55 n$

$\mathrm{M}=\mathrm{MgBr} ; \mathbf{8 6 \%}$

$6 \mathrm{mmol}$ scale (in THF)<smiles>CCCCN(CCC[N+](=O)[O-])C(C(=O)OCC)C(=O)OCC</smiles>

(10) 55j

$M=L i$, THF only $56 \%$<smiles>CCCCCN(c1ccccc1)C(C(=O)OCC)C(=O)OCC</smiles>

(11) $55 \mathrm{k}$

$\mathrm{M}=\mathrm{MgBr} ; 94 \%$

$4 \mathrm{mmol}$ scale<smiles>CCCCN(c1ccccc1[N+](=O)[O-])C(C(=O)OCC)C(=O)OCC</smiles>

(12) 551

$\mathrm{M}=\mathrm{MgBr} ; \mathbf{8 3} \%$<smiles>[CH2+]c1ccc(N(CCCC)C(C(=O)OCC)C(=O)OCC)cc1</smiles>

(13) $55 \mathrm{~m}$

$\mathrm{M}=\mathrm{MgBr} ; \mathbf{9 4 \%}$

$4 \mathrm{mmol}$ scale<smiles>CCCOC(=O)C(C(=O)OCC)N(CCCN)c1cccc(OCCC)c1</smiles>

(15) 550

$\mathrm{M}=\mathrm{MgBr} ; \mathbf{8 1 \%}$

$2.5 \mathrm{mmol}$ scale<smiles>C=Cc1ccccc1N(CCC[N+](=O)[O-])C(C(=O)OCC)C(=O)OCC</smiles>

(16) 55p

$M=M g B r ; 86 \%$<smiles>CCCCCN(c1ccc(OC)c(F)c1)C(C(=O)OCC)C(=O)OCCC</smiles>

(17) $55 q$

$\mathrm{M}=\mathrm{MgBr} ; \mathbf{8 0} \%$

$6 \mathrm{mmol}$ scale (in THF)<smiles>CCCCN(c1cc(F)c(OC)c(Cl)c1)C(C(=O)OCC)C(=O)OCC</smiles>

(20) $55 t$

$\mathrm{M}=\mathrm{MgBr} ; 54 \%$

2 mmol scale (In THF)<smiles>CCCCCN(c1ccc2ccccc2c1)C(C(=O)OCCC)C(=O)OCCCC</smiles>

(21) $55 u$

$\mathrm{M}=\mathrm{MgBr} ; \mathbf{9 5} \%$

$4 \mathrm{mmol}$ scale (In THF)<smiles>CCCCCN(CCc1ccccc1)C(C(=O)OCC)C(=O)OCC</smiles>
$\mathrm{M}=\mathrm{Li}$, THF only $39 \%$<smiles>CCCCN(c1cc(F)cc(OC)c1)C(C(=O)OCC)C(=O)OCC</smiles>

(18) $55 r$

$\mathrm{M}=\mathrm{MgBr} ; 96 \%$

$4 \mathrm{mmol}$ scale (in THF)<smiles>CCCCN(c1cc([N+](=O)[O-])c(F)c([N+](=O)[O-])c1)C(C(=O)OCC)C(=O)OCC</smiles>

(19) $55 \mathrm{~s}$

$\mathrm{M}=\mathrm{MgBr} ; \mathbf{9 1 \%}$

$4 \mathrm{mmol}$ scale (in THF)
(23) $55 w$<smiles>CCCOC(=O)C(C(=O)OCC)N(CCc1ccccc1)c1ccccc1</smiles>

(24) $55 x$

$\mathrm{M}=\mathrm{Li}$, THF only $60 \%$
$M=L i$, THF only; $25 \%$

$\mathrm{M}=\mathrm{MgBr} ; \mathbf{5 4 \%}$<smiles>CCCOC(=O)C(C(=O)OCC)N(CCc1ccccc1)c1cc(F)c(OC)c(F)c1</smiles>

(25) $55 y$<smiles>CCCOC(=O)C(C(=O)OCC)N(c1ccc(C)cc1)C1CCCC1N(c1ccccc1)C1CCCC1</smiles>

(26) $55 z$

$\mathrm{M}=\mathrm{MgBr} ; 82 \%$

$2 \mathrm{mmol}$ scale
(27) $56 a$

$\mathrm{M}=\mathrm{MgBr} ; 66 \%$

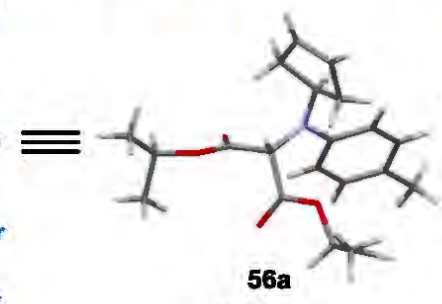

Melting range $=51-55^{\circ} \mathrm{C}$<smiles>CCCOC(=O)C(C(=O)OCC)N(c1cc([N+](=O)[O-])c(O[N+](=O)[O-])cc1[O-])C1CCCC1</smiles>

(28) 56b

$\mathrm{M}=\mathrm{MgBr} ; \mathbf{7 0} \%$

2 mmol scale<smiles>CCCOC(=O)C(C(=O)OCC)N(c1ccccc1)C1CCCCC1</smiles>

(29) $56 \mathrm{c}$

$\mathrm{M}=\mathrm{MgBr} ; 83 \%$

2 mmol scale<smiles>CCCOC(=O)C(C(=O)OCC)N(c1ccccc1)C1CCN(C(=O)OC(C)(C)C)CC1</smiles>

(30) 56d

$\mathrm{M}=\mathrm{MgBr} ; \mathbf{4 8 \%}$

2 mmol scale

Figure 3. Scope of substrates using singly $\mathbf{N}$-electrophilic iminomalonates as aminating agents. All aromatic (52) and aliphatic (53) Grignard reagents have been prepared from the corresponding aryl halides using turnings of freshly activated $\mathrm{Mg}$ metal and THF as solvent. All lithium reagents (MeLi, $n-\mathrm{BuLi}$ and PhLi) were purchased. The concentration of the arylmetal solution was targeted to be around $0.8-1.0 \mathrm{M}$ but was carefully determined by titration immediately before use. The amination reactions were conducted on a $1 \mathrm{mmol}$ scale in DCM/THF (unless indicated otherwise) at the indicated temperature and considered complete upon the full consumption of the individual aminating agents (51) by TLC analysis. 


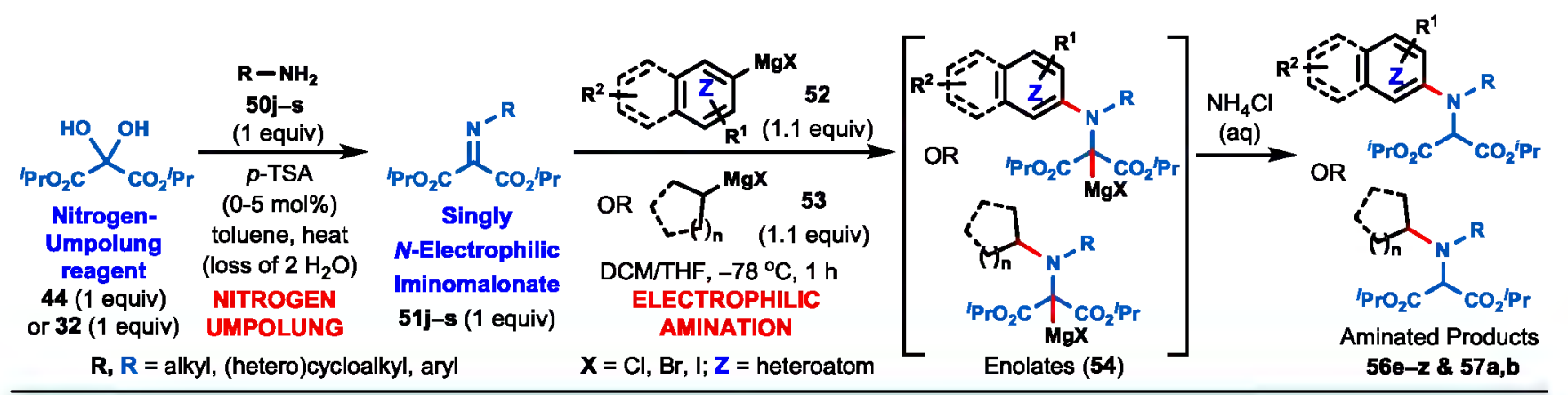

Structure of Unsymmetrical Arylalkyl- and Diarylamine Products

(Entry): Compound \#; Isolated Yield (\%)

Intermolecular Amination of (Cyclo)Alkyl- and (Hetero)Arylmetals With Iminomalonates (continued from Figure 3):<smiles>CCCCC(=O)OC(C(=O)OC(C)C)N(c1ccc2c(c1)CCO2)C1CCN(C(=O)OC(C)(C)C)CC1</smiles>

(31) $56 \mathrm{e}$

$M=M g B r ; 32 \%$<smiles>CCCOC(=O)C(C(=O)OCC)N(c1ccccc1)c1ccc([N+](=O)[O-])cc1</smiles>

(36) 56j

$\mathrm{M}=\mathrm{MgBr} ; \mathbf{5 9} \%$<smiles>CCCOC(=O)C(C(=O)OCC)N(c1ccc([N+](=O)[O-])cc1)c1cccs1</smiles>

(41) 560 $\mathrm{M}=\mathrm{MgBr} ; 61 \%$

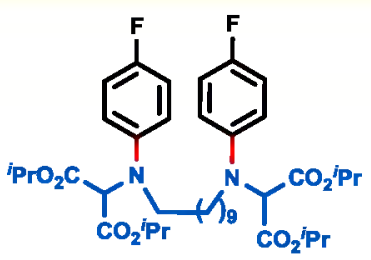

(32) $56 f$ $M=M g B r ; 96 \%$

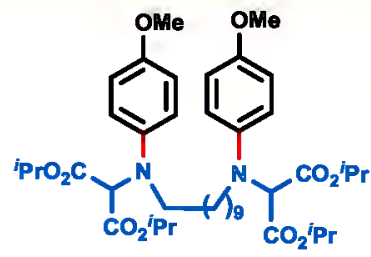

(33) $56 \mathrm{~g}$ $\mathrm{M}=\mathrm{MgBr} ; \mathbf{8 9} \%$

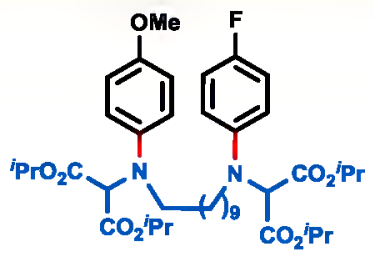

(34) $56 \mathrm{~h}$<smiles>CCCOC(=O)C(C(=O)OCCC)N(Cc1ccccc1)c1ccccc1</smiles>

(35) $56 \mathrm{i}$ $M=M g B r ; 27 \%$

$M=M g B r ; 49 \%$<smiles>CCCCC(=O)C(C(=O)OCC)N(c1ccccc1)c1ccc(S(C)(=O)=O)cc1</smiles>

(37) $56 \mathrm{k}$

$\mathrm{M}=\mathrm{MgBr} ; \mathbf{5 2} \%$<smiles>CCCOC(=O)C(C(=O)OCC)N(c1ccccc1)c1ccc(Oc2ccccc2)cc1</smiles>

(38) 561

$M=M g B r ; 43 \%$<smiles>CCCCC(=O)C(C(=O)OCC)N(c1ccccc1)c1ccc(-c2ccccc2)cc1</smiles>

(39) $56 \mathrm{~m}$

$\mathrm{M}=\mathrm{MgBr} ; 60 \%$<smiles>CCCOC(=O)C(C(=O)OCC)N(c1ccc(C)cc1)c1cccc([N+](=O)[O-])c1</smiles>

(40) 56n

$\mathrm{M}=\mathrm{MgBr} ; \mathbf{5 5} \%$<smiles>CCCCC(C(=O)OCC)N(c1ccc([N+](=O)[O-])cc1)c1csc2ccccc12</smiles>

(42) $56 p$ $\mathrm{M}=\mathrm{MgCl} ; 46 \%$<smiles>CCCCC(=O)C(C(=O)OCC)N(c1ccc(Cl)cc1)c1ccc(OC)cc1</smiles>

(43) 56q $\mathrm{M}=\mathrm{MgBr} ; 36 \%$<smiles>CCOC(=O)C(C(=O)OCC)N(c1ccc(OC)cc1)c1cc([N+](=O)[O-])c(F)c([N+](=O)[O-])c1</smiles>

(44) 56r $\mathrm{M}=\mathrm{MgBr} ; 49 \%$<smiles>CCCC(=O)C(C(=O)OCC)N(c1cccc(-c2ccccc2)c1)c1cc(C(C)C)cc([N+](=O)[O-])c1</smiles>

(49) $56 \mathrm{w}$ $M=M g B r ; 48 \%$<smiles>CCCCC(=O)C(C(=O)OCC)N(c1ccc(CCO)cc1)c1cc(C)c(F)c([N+](=O)[O-])c1</smiles>

(45) $56 \mathrm{~s}, \mathrm{R}=\mathrm{Si}(\mathrm{Me})_{2} t-\mathrm{Bu}$ $\mathrm{M}=\mathrm{MgBr} ; \mathbf{5 7} \%$<smiles>[R]OC(=O)C(C(=O)O[R])N(c1ccc(C#N)cc1)c1ccccc1Br</smiles>

(46) $56 t$

$\mathrm{M}=\mathrm{MgBr} ; \mathrm{R}={ }^{i} \mathrm{Pr} ; \mathbf{1 8 \%}$<smiles>CCCOC(=O)C(C(=O)OCC)N(c1ccc(Cl)cc1)c1cc(C)cc([N+](=O)[O-])c1</smiles>

(47) $56 \mathrm{u}$ $\mathrm{M}=\mathrm{MgBr} ; 33 \%$<smiles>CCCOC(=O)C(C(=O)OCC)N(c1ccc(Oc2ccccc2)cc1)c1cc(C)cc([N+](=O)[O-])c1</smiles>
(48) $56 \mathrm{v}$
$\mathrm{M}=\mathrm{MgBr} ; 35 \%$

$\mathrm{M}=\mathrm{MgBr} ; \mathrm{R}=\mathrm{Et} ; \mathbf{5 6 \%}$<smiles>COC(=O)C(C(=O)OCc1ccccc1)N(c1cc(OC)cc(OC)c1)c1csc2ccccc12</smiles>

(51) $56 \mathrm{y}$

$\mathrm{M}=\mathrm{MgCl} ; \mathbf{7 7 \%}$<smiles>CCCOC(=O)C(C(=O)OCC)N(c1ccc2c(c1)OCO2)c1cccs1</smiles>

(52) $56 z$ $M=M g B r ; 66 \%$<smiles>C=Cc1ccccc1N(c1c(Cl)cccc1Cl)C(C(=O)OCC)C(=O)OCC</smiles>

(53) 57a

$M=M g B r ; 64 \%$<smiles>CCCC(=O)C(C(=O)OCC)N(c1cc([N+](=O)[O-])cc([N+](=O)[O-])c1)c1cc([N+](=O)[O-])c(F)c([N+](=O)[O-])c1</smiles>

(50) $56 x$

Figure 4. Scope of substrates using singly $\mathrm{N}$-electrophilic iminomalonates (51) as aminating agents. All aromatic (52) and aliphatic (53) Grignard reagents have been prepared from the corresponding aryl halides using turnings of freshly activated $\mathrm{Mg}$ metal and THF as the solvent. The concentration of the arylmetal solution was targeted to be around $0.8-1.0 \mathrm{M}$ but was carefully determined by titration immediately before use. The amination reactions were conducted on a $1 \mathrm{mmol}$ scale at the indicated temperature and considered complete upon the full consumption of the individual aminating agents (51) by TLC analysis. 
both the ketomalonate hydrate (44) and oxime $O$-tosylate (47) reagents were obtained using single crystal X-ray crystallography (Figure 2, H). We were pleased to find that di-isopropyl ketomalonate hydrate (44) smoothly underwent condensation with both aliphatic and aromatic primary amines and the corresponding $\mathrm{N}$ substituted iminomalonates (48 \& 49) were isolated in good to excellent yields (Figure 2, I).

The highly encouraging results presented in Figure 2 allowed us to begin exploring the full scope and limitations of our fundamentally new and general single and double $\mathrm{N}$-umpolung method (Figures. 3-5). First, ten different acyclic and cyclic primary aliphatic amines $(\mathbf{5 0 a}-\mathbf{j})$ were condensed with nitrogen-umpolung reagent 44 (Figure 3) and the corresponding bench-stable singly $N$-electrophilic iminomalonates $(\mathbf{5 1})$ were treated with twenty-one (21) different aromatic and aliphatic Grignard as well as lithium reagents. In each case, electrophilic amination took place rapidly at low temperature to afford aminated products $\mathbf{5 5} \mathbf{a}-\mathbf{z} \& \mathbf{5 6} \mathbf{a}-\mathbf{h}$. The following examples in Figures. $3 \& 4$ are particularly noteworthy: (a) $N$-cyclopropyl iminomalonate (51d) allowed the rapid preparation of not only $N, N$-dicyclopropyl- and $N$-cyclobutyl- $N$-cyclopropyl amines (55 $\&$ 55g) but also $N$-arylated derivatives $(\mathbf{5 5} \mathbf{h} \&$ 55i); (b) $N$-butyl iminomalonate (51e, entries 11-21) underwent smooth $\mathrm{N}$-arylation by a set of eleven structurally and electronically diverse aryl Grignard reagents to give uniformly high yields of the corresponding arylalkyl amine derivatives (55k-u); (c) $\mathrm{N}$-cyclopentyl (519) and $\mathrm{N}$ cyclohexyl (5ih) as well as $N$-(4-piperidinyl) (5ıi) iminomalonates furnished six $N$-(hetero)arylated products $(55 z \& 56 a-e$, Figure 3 \& Figure 4 ) in moderate to good isolated yields; (d) di-iminomalonate 51j (entries 32-34) derived from an aliphatic $\alpha, \omega$-diamine (50j) could be efficiently di- $N$-arylated with two equivalents of an aryl Grignard reagent to afford the corresponding symmetrical diamines ( $56 \mathbf{f} \& \mathbf{5 6 g}$, Figure 4 ), however, only a modest yield of the unsymmetrical diamine (56h, entry 34$)$ was obtained when two different aryl Grignard reagents were added sequentially.

The latter example clearly demonstrates the feasibility and future potential of using two different arylmetals for sequential $\mathrm{C}-\mathrm{N}$ bond-formation, however, this process still requires optimization; (e) nine (9) different $\mathrm{N}$-aryliminomalonates (51k-s, Figure 4), derived from aromatic amines (5ok-s), were exposed to thirteen (13) different aryl Grignard reagents to produce nineteen (19) unsymmetrical $N, N$-diarylamine products $\left({ }_{5} 6 \mathbf{j}-\mathbf{z} \& 57 \mathbf{a} \& 57 \mathbf{b}\right)$ in moderate to good isolated yields; (f) sterically hindered (i.e., mostly ortho-substituted) arylamines not only gave significantly higher yields of the corresponding iminomalonates when condensed with a sterically less hindered ketomalonate (32), but were also more efficiently $\mathrm{N}$ arylated with sterically hindered aryl Grignard reagents (56t, 57a \& 57b). The last three examples showcase the fact that the structure of the reactivity-modifying umpolung reagent can be adjusted to match the structural variations in both the primary amine substrates and aryl
Grignard reagents, in order to obtain synthetically useful yields of the desired diarylamine products.

Next, we explored the scope and limitations of doubly $\mathrm{N}$ electrophilic iminomalonates (47a-c, Figure 5) as nitrogen linchpin agents. Fifteen (15) different arylmetals (52), representing diverse steric and electronic properties, were coupled to furnish symmetrical diarylamines $(59 a-0)$ in moderate to good yields. As anticipated, sterically hindered arylmetals (entries 62-65 \& 69; Figure 5) were coupled with much greater efficiency when the ester groups on the nitrogen linchpin reagents were sterically less encumbered $(\mathbf{4 7} \mathbf{b} \& \mathbf{c}, \mathrm{R}=\mathrm{Me}$ or Et). For all other arylmetal substrates, the more sterically hindered di-isopropyl linchpin reagent (47a) proved to be ideal. A thorough study of the literature revealed that the preparation of symmetrical diarylamines is far from being a trivial task as it often requires two different functionalities (e.g., arylboronic acid and arylamine or aryl halide and arylamine) to be cross-coupled in the presence of transition metal catalysts. ${ }^{42}$ Therefore, utilization of a doubly electrophilic nitrogen linchpin reagent in combination of two equivalents of a particular arylmetal reagent at low temperature qualifies this approach, to the best of our knowledge, as both the fastest and mildest for the preparation of this valuable class of aromatic compounds.

Density-functional calculations (Mo6-2X/def2-TZVP, see SM for details of calculations in THF and DCM as solvents) provide mechanistic and reactivity insights into the success of the diarylation of $\mathbf{4 7}$ with $\mathrm{PhMgBr}$. Previous computational studies suggest that a single-step concerted $N$-substitution can occur at $\mathrm{sp}^{2}$-hybridized nitrogen atoms with leaving groups ( $O$-methanesulfonyl and $O-p$ toluenesulfonyl). $43-45$ However, the one-step $\mathrm{S}_{\mathrm{N} 2 \text {-type }}$ transition state between $(\mathrm{PhMgBr})_{2}$ and the methyl ester linchpin reagent $\mathbf{4 7} \mathbf{b}$ has a $\Delta G^{\ddagger}>30 \mathrm{kcal} / \mathrm{mol}$. This is a much larger barrier than the alternative stepwise mechanism that involves an addition-elimination sequence via ${ }_{T} S_{1}$ and $\mathbf{T S}_{\mathbf{2}}$ as shown in Figure ${ }_{5} \mathrm{~B}$. TS $\mathbf{1}$ that has coordination between the $(\mathrm{PhMgBr})_{2}$ and the OMs group requires $\Delta G^{\ddagger}=10.4 \mathrm{kcal} / \mathrm{mol}$ and generates a highly stabilized intermediate $(\Delta \mathrm{G}=-52.4 \mathrm{kcal} / \mathrm{mol})$ due to the presence of the two ester functional groups. Ejection of the mesylate anion $\left(\mathrm{MsO}^{-}\right)$from this intermediate via TS2 requires $\Delta G^{\ddagger}$ $=15.0 \mathrm{kcal} / \mathrm{mol}$ (relative to the intermediate) and results in the formation of $\mathrm{N}$-phenyl iminomalonate. Our calculations indicate that the transition state for aryl Grignard addition to the ester is disfavored with a $\Delta G^{\ddagger}>20$ $\mathrm{kcal} / \mathrm{mol}$ barrier. This computational model also shows that the transition state for $\mathrm{N}$-attack is slightly lower in energy than for $C$-attack (see SM). The $\Delta G^{\ddagger}$ for phenyl addition to the $N$-phenyl iminomalonate requires $\Delta G^{\ddagger}=$ $19.4 \mathrm{kcal} / \mathrm{mol}$ and is slightly larger than the barrier for Grignard addition to $\mathbf{4 7}$ with the more electron-deficient nitrogen. While the second aryl Grignard addition is slower, the $\mathrm{N}, \mathrm{N}$-diarylated product is observed because the Grignard reagent likely reacts as a multinuclear species, such as $(\mathrm{PhMgBr})_{2}$, and does not separate from the $\mathrm{N}$-phenyl iminomalonate intermediate (Figure 5). 


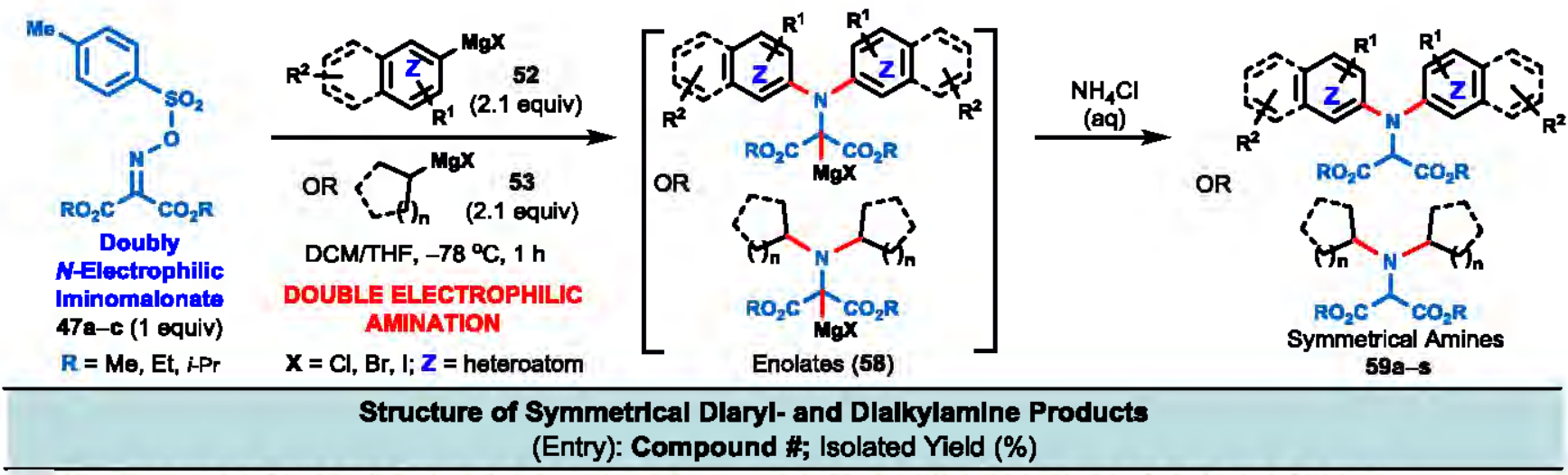

A Intermolecular Double (Linchpin) Amination of Aryl- and (Cyclo)alkylmetals With O-Sulfonyl Oximes:<smiles>CCCOC(=O)C(C(=O)OCC)N(c1ccccc1)c1ccccc1</smiles>

(55) $59 a$

$\mathrm{M}=\mathrm{MgBr} ; \mathbf{7 5 \%}$<smiles>CCCC(=O)C(C(=O)OC)N(c1ccc(C)cc1)c1ccc([N+](=O)[O-])cc1</smiles>

(56) $59 \mathrm{~b}$

$\mathrm{M}=\mathrm{MgBr} ; \mathbf{7 3} \%$<smiles>CCCCC(=O)C(C(=O)OCC)N(c1ccc(Cl)cc1)c1ccc(Cl)cc1</smiles>

(57) $59 \mathrm{c}$<smiles>COC(=O)C(C(=O)OC)N(c1ccc(-c2ccccc2)cc1)c1ccc(-c2ccccc2)cc1</smiles>

(60) $59 f$

$\mathrm{M}=\mathrm{MgBr} ; 60 \%$<smiles>CCCOC(=O)C(C(=O)OCC)N(c1cccc(-c2ccccc2)c1)c1cccc(-c2ccccc2)c1</smiles>

(61) $59 \mathrm{~g}$ $M=M g B r, 65 \%$<smiles>CCCCC(=O)C(C(=O)OC)N(c1ccc([As])cc1)c1ccc(S(C)(=O)=O)cc1</smiles>

(58) 59d $\mathrm{M}=\mathrm{MgBr} ; 45 \%$<smiles>CCCOC(=O)C(C(=O)OCC)N(c1ccc(Oc2ccccc2)cc1)c1ccc(Oc2ccccc2)cc1</smiles>

(59) 590

$\mathrm{M}=\mathrm{MgBr}, \mathbf{4 1 \%}$<smiles>C=CCc1ccccc1N(c1ccccc1CC=C)C(C(=O)OCC)C(=O)OCC</smiles>

(63) $59 \mathrm{i}$ $\mathrm{M}=\mathrm{MgBr} ; 26 \%$<smiles>CC(=O)C(C(=O)O[Na])N(c1cccc(Cl)c1Cl)c1cccc(Cl)c1Cl</smiles>

(64) 59j

$\mathrm{M}=\mathrm{MgBr} ; 54 \%$<smiles>CC(=O)C(C(C)=O)N(c1ccc(Cl)cc1[18O])c1ccc(Cl)cc1[N+](=O)[O-]</smiles>

(65) 59k

$M=M g B r ; 72 \%$<smiles>CCCOC(=O)C(C(=O)OCC)N(c1cc(F)cc(F)c1)c1cc(F)cc([N+](=O)[O-])c1</smiles>

(66) 59

$\mathrm{M}=\mathrm{MgBr} ; 29 \%$<smiles>COC(=O)C(C(=O)OC(C)C)N(c1cc(OC)cc([N+](=O)[O-])c1)c1cc([N+](=O)[O-])c(OC)c([N+](=O)[O-])c1</smiles>

(67) $59 \mathrm{~m}$ $M=M g B r ; 67 \%$
(62) $59 \mathrm{~h}$ $\mathrm{M}=\mathrm{MgBr}, 47 \%$<smiles>CCCOC(=O)C(C(=O)OCC)N(c1cc(F)c(F)c([N+](=O)[O-])c1)c1cc([N+](=O)[O-])c(F)c([N+](=O)[O-])c1</smiles>

(68) $59 n$ $\mathrm{M}=\mathrm{MgBr} ; 45 \%$<smiles>COc1cc(C)c(N(c2cc([N+](=O)[O-])c(OC)cc2[N+](=O)[O-])C(C(=O)O)C(=O)O)cc1[N+](=O)[O-]</smiles>

(69) 590<smiles>CCCOC(=O)C(C(=O)OCC)N(Cc1ccccc1)Cc1ccccc1</smiles><smiles>CCCOC(=O)C(C(=O)OCC)N(C1CCC1)C1CCC1</smiles>

(70) 59p

$\mathrm{M}=\mathrm{MgBr}, 53 \%$

(71) 59q

$\mathrm{M}=\mathrm{MgBr} ; 38 \%$

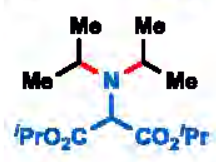

(72) 59r

\section{B Computatlonally determined posslble transition state (TS) structures}

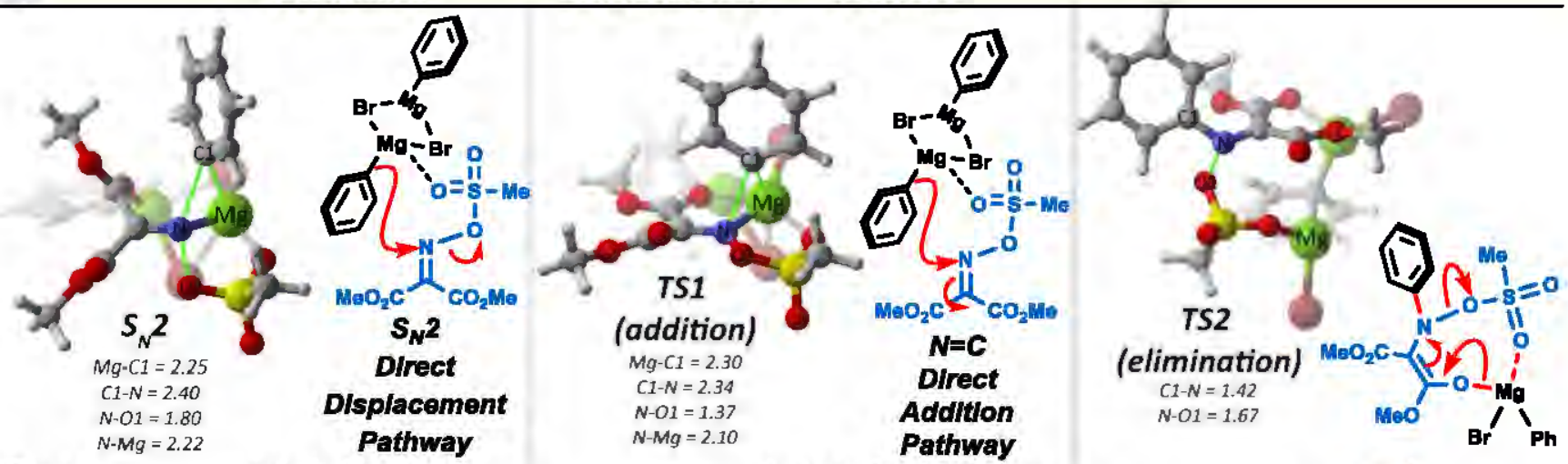

Figure 5. Scope of substrates using a doubly $\mathrm{N}$-electrophilic iminomalonate (47) as linchpin aminating agent and computed possible transition state (TS) structures. (A) The amination reactions were conducted on a $1 \mathrm{mmol}$ scale at the indicated temperature and considered complete upon the full consumption of the individual aminating agents (47a-c) by TLC analysis. (B) Structures of three possible transition states. 


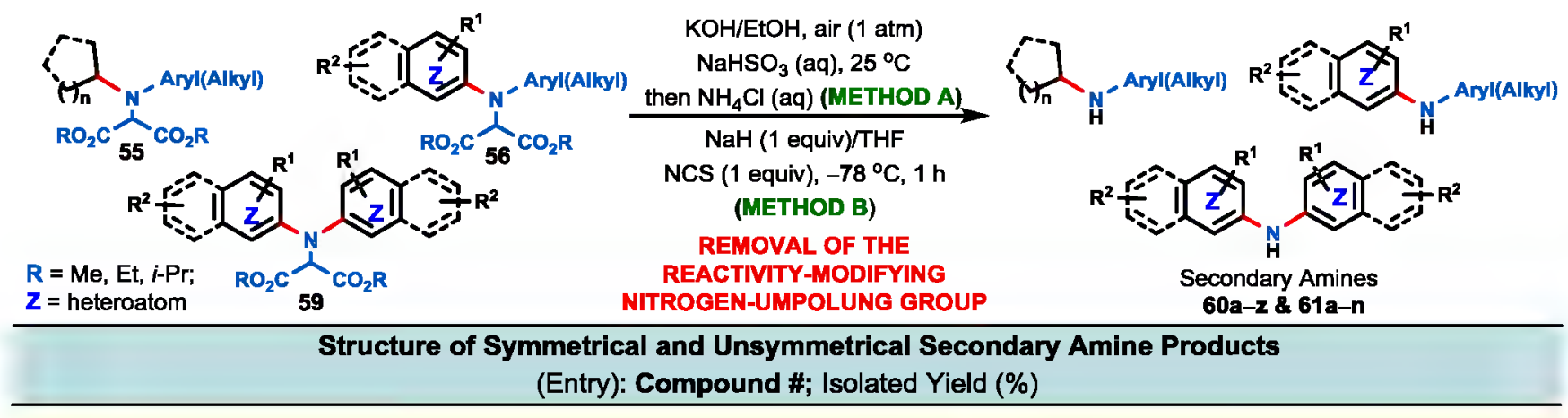

Oxidative Removal of the Reactivity-Modifying Nitrogen Umpolung Group to Furnish Secondary Amines:<smiles>C=Cc1ccccc1NCCCC</smiles><smiles>O=[N+]([O-])c1cc(Nc2cc([N+](=O)[O-])c(F)c([N+](=O)[O-])c2)cc(O)c1F</smiles><smiles>COc1cc(Nc2cc([N+](=O)[O-])c(OC)c([N+](=O)[O-])c2)cc([N+](=O)[O-])c1OC</smiles><smiles>c1ccc(Nc2ccc(-c3ccccc3)cc2)cc1</smiles>

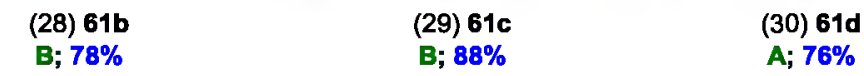<smiles>CC(C)(C)[13C](C)(C)C</smiles>

(33) $61 \mathrm{~g}$<smiles>Cc1ccc(Nc2cccc([N+](=O)[O-])c2)cc1</smiles>

(34) $61 \mathrm{~h}$<smiles>COc1ccc(Nc2ccc(Cl)cc2)cc1</smiles>

(35) 611<smiles>COc1ccc(Nc2cc(O)c(F)c([18OH])c2)cc1</smiles>

(36) 61j B; $74 \%$
(32) $61 f$

B; $61 \%$<smiles>O=[N+]([O-])c1cc(Nc2ccc(Cl)cc2)cc([N+](=O)[O-])c1</smiles>

(37) $61 \mathrm{k}$<smiles>O=[N+]c1cc(Nc2cccc(-c3ccccc3)c2)cc([N+](=O)[O-])c1</smiles>

(38) 611

B; $77 \%$<smiles>O=[N+]([O-])c1cc(Nc2ccc(Oc3ccccc3)cc2)cc([N+](=O)[O-])c1</smiles>

(39) $61 \mathrm{~m}$

B; $82 \%$<smiles>Cc1cc(Nc2cc(C)c(F)c([N+](=O)[O-])c2)cc([N+](=O)[O-])c1</smiles>

(40) $61 \mathrm{n}$<smiles>Cc1ccc(Nc2ccccc2Br)cc1</smiles>

(41) 610

B; $67 \%$

Figure 6. Removal of the dialkylmalonyl group under oxidative conditions. The symmetrical and unsymmetrical secondary amine products, obtained after the $\mathrm{C}-\mathbf{N}$ bond formation, were subjected to either one of the two conditions (A or $B$ ). 


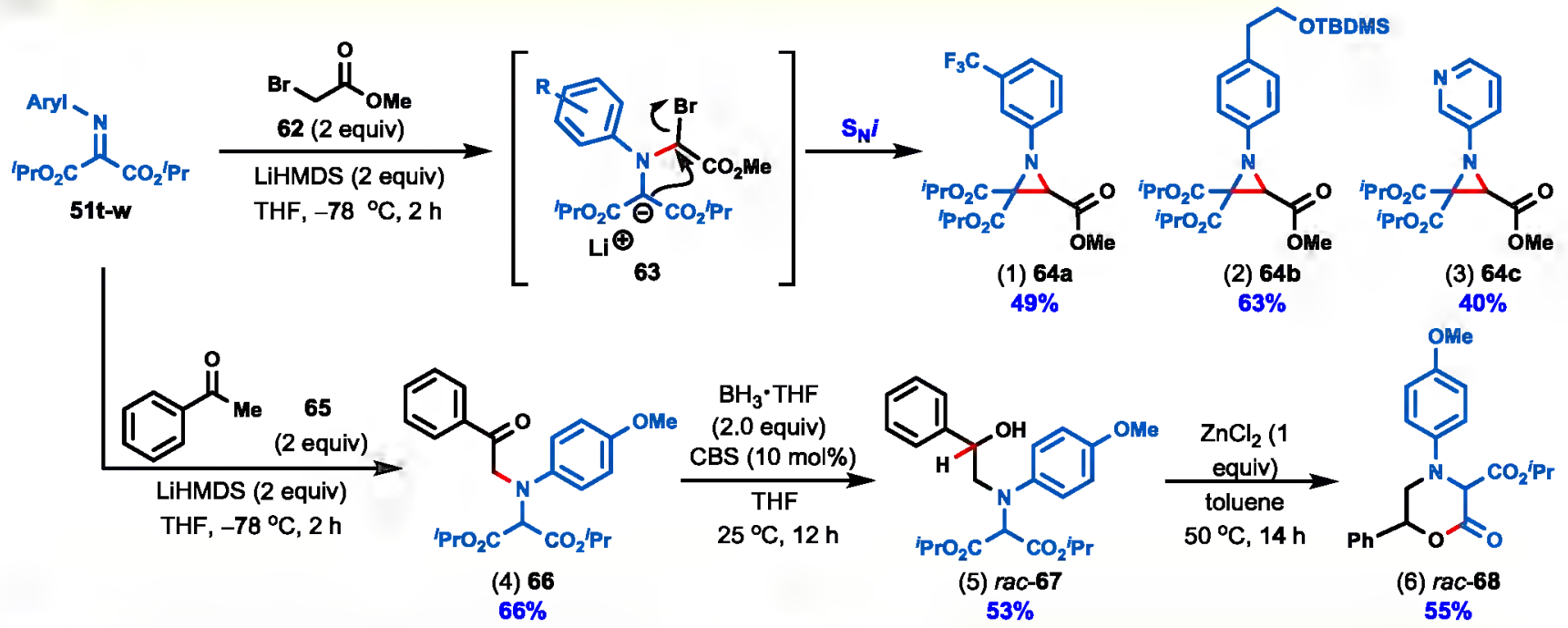

B Preparation of a Diversely Substituted Carbazole:

C Preparation of an Aromatic Amino Acid Derivative:

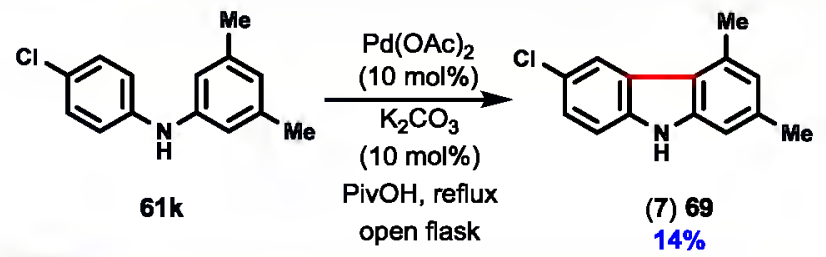

D Preparation of Medium-Sized $\mathbf{N}$-Heterocycles:<smiles>C=Cc1ccccc1N(c1ccccc1C=C)C(C(=O)O)C(=O)OCC</smiles>

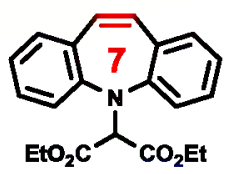

(9) $71 ; 61 \%$

Carbamazepine skeleton<smiles>C=CCc1ccccc1N(c1c(Cl)cccc1Cl)C(CC)C(=O)OCC</smiles>

57b

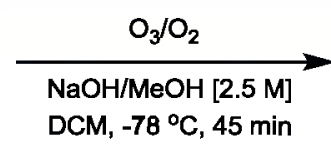

$\mathrm{NaOH} / \mathrm{MeOH}[2.5 \mathrm{M}]$

D.M.<smiles>CCOC(=O)C(C(=O)OCC)N(c1ccccc1CC(=O)OC)c1c(Cl)cccc1Cl</smiles>

(8) $70 ; 50 \%$

Diclofenac skeleton

Figure 7. Demonstrating additional synthetic possibilities for $N$-electrophilic iminomalonates and $N, N$-diarylamines.

(A) Besides hard C-nucleophiles such as aryl Grignard reagents and alkyl/aryllithiums, softer $C$-nucleophiles derived from esters and ketones also readily add to the nitrogen of iminomalonates. The Li-enolate of 62 underwent spontanaoeus aziridine ring-formation with three different $\mathrm{N}$-aryl iminomalonates. Aminoketone 66 could be reduced to the corresponding aminoalcohol 67 which underwent Lewis acid-mediated ring closure to afford highly substituted morpholine derivative 68. (B) Substituted $N$-unprotected unsymmetrical $N, N$-diarylamine $61 \mathrm{k}$ underwent dehydrogenative cross-coupling to afford the corresponding carabazole 69. (C) The skeleton of the non-steroidal anti-inflammatory drug (NSAID) Diclofenac (70) was synthesized from diarylamine 57b in one step - importantly, the key aryl-nitrogen linkage in compound $\mathbf{7 0}$ was prepared from readily available building blocks in the absence of transition metal catalysts. (C) Ring-closing metathesis of di-ortho vinyl-substituted as well as di-ortho allyl-substituted diarylamines $59 \mathrm{~h} \& \mathbf{5 9 i}$ afford 7 - and 9 -membered $\mathrm{N}$-heterocycles 71 \& 72, respectively. Compound 71 contains the skeleton of the anti-seizure medicine carbamazepine while the ring system in compound $\mathbf{7 2}$ is brand new.

The considerable synthetic power of these two novel $\mathrm{C}-\mathrm{N}$ bond-forming methods ( 54 examples in Figure 3 \& Figure 4 and 19 examples in Figure 5) becomes even more apparent when one considers the very high number $(>3,000)$ of commercially available and structurally diverse arylamine, aryl halide or arylmetal substrates that could be crosscoupled. There are several advantages of this $\mathrm{N}$-umpolung approach over existing metal-catalyzed/mediated meth- ods, but perhaps the operational simplicity and mild reaction conditions are the two most important ones.

At first glance, the presence of the dialkylmalonyl substituent on the nitrogen atom of the singly and doubly aminated compounds $(\mathbf{5 5}, \mathbf{5 6}, \mathbf{5 7} \& \mathbf{5 9})$ seems problematic as the $N$-malonyl $\mathrm{C}-\mathrm{N}$ linkage has to be cleaved in order to reveal the free dialkyl-, arylalkyl- and diarylamine products (6o \& 61, Figure 6). In fact, the $N$-malonyl group effectively protects the electron-rich amine products from 
the common oxidative decomposition pathways that usually occur in the presence of light and oxygen. Fortunately, this temporary protecting group can be effectively removed on demand either by using (1) mildly basic conditions and air at room temperature (Method A) or (2) a base and a mild oxidant, such as $\mathrm{N}$-chloro succinimide (NCS), at low temperature (Method B, Figure 6). Forty (40) structurally diverse $N$-malonyl substrates were subjected to one or both of these conditions and we found that Method B was far more general than Method A and afforded the $\mathrm{N}$-deprotected secondary amine products (6o \& 61) in good to excellent isolated yields. It is noteworthy that the oxidative cleavage of the $\mathrm{N}$-malonyl $\mathrm{C}-\mathrm{N}$ bond effectively regenerates the ketomalonate (43) and/or ketomalonate hydrate (44) umpolung reagents that can be recovered and reused if desired.

Besides the dozens of successful electrophilic aminations using hard $C$-nucleophiles (Figures. 3-5), we also wanted to demonstrate the ability of the $\mathrm{N}$-electrophilic iminomalonates to undergo $\mathrm{C}-\mathrm{N}$ bond-formation with softer $C$-nucleophiles such as enolates (Figure 7). Indeed, the lithium enolate derived from $\alpha$-bromoester $\mathbf{6 2}$ reacted with three different $N$-aryl iminomalonates $(\mathbf{5 2 t}-\mathbf{v})$ to afford the corresponding $N$-aryl aziridines $(\mathbf{6 4 a} \mathbf{a}-\mathbf{c})$ in onepot via presumptive intermediate $\mathbf{6 3}_{3}$ (Figure $7, \mathbf{A}$ ). These are remarkable examples of the aza-Darzens reaction that usually requires the presence of a strongly electronwithdrawing moiety on the nitrogen atom. ${ }^{46-47}$ The lithium enolate derived from acetophenone $\mathbf{6 5}$ reacted with imine $51 w$ to furnish $\alpha$-aminoaryl ketone 66 that was converted further to a brand new and highly-substituted morpholine (68) in two steps via a Lewis acid-mediated cyclization of amino alcohol $6_{7}$.

Unsymmetrical diarylamine $\mathbf{6 1 k}$ yielded a rare carbazole 69 under Fagnou's dehydrogenative cross-coupling conditions, however this process requires considerable optimization in order to be reliable on large-scale (Figure $7, \mathbf{B}$ ). $4^{8}$ We also demonstrated that the sterically hindered diarylamine skeleton of the non-steroidal anti-inflammatory drug (NSAID) diclofenac $\mathbf{7 0}$ could be readily prepared in just two steps from the $N$-arylated compound $\mathbf{5 7} \mathbf{b}$ without using transition metal catalysts or harsh reaction conditions (Figure 7, C). ${ }^{49}$

Finally, medium-sized nitrogen-containing ring-systems could be prepared from $N$-linchpin products $59 \mathbf{h} \& \mathbf{5 9 i}$. Under ring-closing metathesis conditions these compounds smoothly cyclized to the corresponding $7^{-}$and 9membered $\mathrm{N}$-heterocycles (Figure $7, \mathbf{D}$ ). The 7 -membered compound contains the skeleton of the anti-seizure medicine Carbamazepine ${ }^{\mathrm{TM}}$. Based on this efficient synthetic route, one can envision the rapid and straightforward synthesis of a library of structurally diverse carbamazepine analogs in which no catalyst/ligand optimizations would be required for the $\mathrm{C}-\mathrm{N}$ bond-forming step.

The transformations displayed in Figure 7 provide a glimpse at the potentially vast number of synthetic possibilities that the single and double umpolung of nitrogen will enable organic chemists to exploit for the synthesis of nitrogen-containing compounds.

\section{Conclusion}

With the successful development of a practical single and double umpolung of nitrogen, synthetic organic and medicinal chemists now have unprecedented flexibility in terms of $\mathrm{C}-\mathrm{N}$ bond-disconnections when outlining the most efficient synthetic routes to their target compounds. This fundamentally new and non-catalytic approach for the preparation of amines not only provides an alternative to currently used $\mathrm{C}-\mathrm{N}$ cross-coupling methods, but may also be combined with a wide variety of existing metalcatalyzed transformations for the elaboration of the initially obtained products. It is anticipated that the $\mathrm{N}$ electrophilic iminomalonates described in this manuscript will also find use as coupling partners in transition metal-catalyzed, organocatalytic as well as in photoredox/radical C $-\mathrm{N}$ bond-forming processes to provide convenient synthetic access to a vast array of structurally diverse nitrogen-containing compounds.

\section{ASSOCIATED CONTENT}

Complete experimental procedures and characterization data including ${ }^{1} \mathrm{H},{ }^{13} \mathrm{C}$ and ${ }^{19} \mathrm{~F}$ NMR spectra, single crystal X-ray crystallographic data for compounds $\mathbf{4 4}, 47$ and $56 \mathbf{6}$ as well as differential scanning calorimetry (DSC) data and analysis for compounds 38a, 44, 47, 47a, 47b, 47c, 47d, 47e, 47f, 47g, 47h and $47 \mathbf{i}$. This material is available free of charge via the Internet at http://pubs.acs.org.

\section{AUTHOR INFORMATION}

\section{Corresponding Author}

kurti.laszlo@rice.edu;dhe@chem.byu.edu; guigenli@nju.edu.cn

\section{Notes}

The authors declare no competing financial interest.

\section{ACKNOWLEDGMENT}

This manuscript is dedicated to Professor Madeleine $\mathrm{M}$. Joullié on the occasion of her $90^{\text {th }}$ birthday.

L.K. gratefully acknowledges the generous financial support of Rice University, the National Institutes of Health (Ro1 GM114609-01), the National Science Foundation (CAREER:SusChEM CHE-1546097), the Robert A. Welch Foundation (grant C-1764), Amgen (2014 Young Investigators' Award for LK) and Biotage (2015 Young Principal Investigator Award) that are greatly appreciated. We thank ICBMS/Nanjing University for a postdoctoral fellowship supporting P.V. Kattamuri. D.H.E. thanks BYU and the Fulton Supercomputing Lab. G.L. acknowledges the generous support of the National Science Foundation of China (NSFC grants No. 21332005 and 21672100). X-Ray crystallographic data was collected at the Center for Nanostructured Materials at the University of Texas at Arlington. We thank Pfizer LaJolla for allowing the collection of DSC data on the electrophilic aminating reagents used in this manuscript the full DSC analysis and interpretation data is included in the Supporting Information. We appreciate the help of Dr. 
Lawrence B. Alemany (Rice University) for the acquisition and analysis of 29 fluorine NMR spectra. We also thank G. Bellavance, T. Benkovics, S. E. Denmark, Z.G. Hajos, M.M. Joullié, O. Larionov, J. Lopchuk, I. Marek, K.C. Nicolaou, J. T. Njardarson, M. Pavia, E. Pitsinos, D. Richter, D. Rhoades, S. Rigol, A. Toro and D. Vourloumis for helpful commentary.

\section{REFERENCES}

1. Ricci, A.; Editor, Amino Group Chemistry: From Synthesis to the Life Sciences. Wiley-VCH: Weinheim, 2008; p 394.

2. Hili, R.; Yudin, A. K., Nat. Chem. Biol. 2006, 2, 284-287.

3. Rappoport, Z.; Editor, The Chemistry of Anilines, Parts 1-2. John Wiley \& Sons: Chichester, 2007.

4. Kürti, L., Science 2015, 348, 863-864

5. Monnier, F.; Taillefer, M., Copper-catalyzed C(aryl)-N bond formation. In Top. Organomet. Chem., Springer verlag: Berlin, 2013; Vol. 46 (Amination and Formation of sp ${ }^{2}$ C-N Bonds), pp 173-204.

6. Wolfe, J. P.; Wagaw, S.; Marcoux, J.-F.; Buchwald, S. L., Acc. Chem. Res. 1998, 31, 805-818.

7. Buchwald, S. L.; Mauger, C.; Mignani, G.; Scholz, U., Adv. Synth. Catal. 2006, 348, 23-39.

8. Surry, D. S.; Buchwald, S. L., Chem. Sci. 2011, 2, 27-50.

9. Corcoran, E. B.; Pirnot, M. T.; Lin, S.; Dreher, S. D.; DiRocco, D. A.; Davies, I. W.; Buchwald, S. L.; MacMillan, D. W. C., Science 2016, 353, 279-283.

10. Qiao, J. X.; Lam, P. Y. S., Recent advances in Chan-Lam coupling reaction: copper-promoted C-heteroatom bond cross-coupling reactions with boronic acids and derivatives. In Boronic Acids (2nd Edition), Hall, D. G., Ed. Wiley-VCH: Weinheim, 2011; Vol. 1, pp 315-361.

11. Qiao, J. X.; Lam, P. Y. S., Synthesis 2011, 829-856.

12. Shin, K.; Kim, H.; Chang, S., Acc. Chem. Res. 2015, 48, 1040-1052.

13. Paudyal, M. P.; Adebesin, A. M.; Burt, S. R.; Ess, D. H.; Ma, Z.; Kürti, L.; Falck, J. R., Science 2016, 353, 1144-1147.

14. Romero, N. A.; Margrey, K. A.; Tay, N. E.; Nicewicz, D. A., Science 2015, 349, 1326-1330.

15. Yan, X.; Yang, X.; Xi, C., Catal. Sci. Technol. 2014, 4, 4169-4177.

16. Zhou, Z.; Ma, Z.; Behnke, N. E.; Gao, H.; Kürti, L., J. Am. Chem. Soc. 2017, 139, 115-118.

17. Sapountzis, I.; Knochel, P., J. Am. Chem. Soc. 2002, 124, 93909391.

18. Cheung, C. W.; Hu, X., Nat. Commun. 2016, 7, 12494.

19. Gao, H.; Xu, Q.-L.; Yousufuddin, M.; Ess, D. H.; Kürti, L., Angew. Chem., Int. Ed. 2014, 53, 2701-2705.

20. Gui, J.; Pan, C.-M.; Jin, Y.; Qin, T.; Lo, J. C.; Lee, B. J.; Spergel, S. H.; Mertzman, M. E.; Pitts, W. J.; La Cruz, T. E.; Schmidt, M. A.; Darvatkar, N.; Natarajan, S. R.; Baran, P. S., Science 2015, 348 , 886-891

21. Aksenov, A. V.; Aksenov, N. A.; Orazova, N. A.; Aksenov, D. A.; Dmitriev, M. V.; Rubin, M., RSC Adv. 2015, 5, 84849-84855.

22. Thome, I.; Bolm, C., Org. Lett. 2012, 14, 1892-1895.

23. Qiu, F.; Norwood, D. L., J. Liq. Chromatogr. Relat. Technol. 2007, 30, 877-935

24. Welch, C. J.; Albaneze-Walker, J.; Leonard, W. R.; Biba, M.; DaSilva, J.; Henderson, D.; Laing, B.; Mathre, D. J.; Spencer, S.; Bu, X.; Wang, T., Org. Process Res. Dev. 2005, 9, 198-205.

25. Garrett, C. E.; Prasad, K., Adv. Synth. Catal. 2004, 346, 889-900.

26. Schmitz, E., Russ. Chem. Rev. 1976, 45, 16-24.

27. Erdik, E.; Ay, M., Chem. Rev. 1989, 89, 1947-80

28. Ciganek, E., Electrophilic amination of carbanions, enolates, and their surrogates. John Wiley \& Sons: Hoboken, NJ, U. S., 2008; Vol. 72, p 1-366.

29. Erdik, E., Electrophilic C-amination with O-substituted hydroxylamines, oximes and O-substituted oximes. In Chemistry of Hydroxylamines, Oximes and Hydroxamic Acids, Pt. 1 ed.; Patai, S., Ed. John Wiley \& Sons Ltd.: Chichester, 2009; Vol. 1, pp 303-341.

30. Dong, X.; Liu, Q.; Dong, Y.; Liu, H., Chem. Eur. J 2017, 23, 24812511.

31. Fiaud, J. C.; Kagan, H. B., Tetrahedron Lett. 1970, 1813-6.

32. Mizota, I.; Shimizu, M., Chem. Rec. 2016, 16, 688-702.
33. Niwa, Y.; Takayama, K.; Shimizu, M., Tetrahedron Lett. 2001, 42, 5473-5476.

34. Nohira, H.; Sato, K.; Mukaiyama, T., Bull. Chem. Soc. Jpn. 1963, $36,870-2$.

35. Gao, H.; Zhou, Z.; Kwon, D.-H.; Coombs, J.; Jones, S.; Behnke, N. E.; Ess, D. H.; Kürti, L., Nat. Chem. 2016, 9, 681-688.

36. Zhu, C.; Li, G.; Ess, D. H.; Falck, J. R.; Kürti, L., J. Am. Chem. Soc. 2012, 134, 18253-18256.

37. A thorough solvent study (see the SI on page S58) revealed that while $\mathrm{N}$-attack was favored for imine $\mathbf{4 0}$, the proportion of the $\mathrm{C}$ attack product was generally high (e.g., 53\% $\mathrm{N}$-attack along with $32 \%$ of C-attack product in DCM/THF). In addition, the cost of ditert-butyl malonate (38) is significantly more than that of diisopropyl malonate (37) and also the preparation of the diol $\mathbf{4 4}$ from 37 proceeds with better efficiency than the corresponding diol from 38 (52\% versus $68 \%$, see the SI for more details)

38. Sivan, A.; Deepthi, A., Tetrahedron Lett. 2014, 55, 1890-1893.

39. Tietze, L. F.; Bratz, M., Org. Synth. 1993, 71, 214-19.

40. Peng, X.; Zhu, Y.; Ramirez, T. A.; Zhao, B.; Shi, Y., Org. Lett. 2011, 13, 5244-5247.

41. Differential scanning calorimetry (DSC) data were collected and analyzed (see the SI) on all of the aminating agents described in this manuscript to assess their thermal stability and evaluate their safety. The DSC data were collected on a TA Instruments Q1000 equipped with a RSC90 (refrigerated cooling system) using sealed standard aluminum hermetic pans (note for more rigorous safety evaluation, we recommend the use of gold-plated high pressure crucibles, and hence only onset temperatures are reported in the SI), and the samples were crimped closed. The typical ramp tests were conducted using the following parameters: hold sample at $30{ }^{\circ} \mathrm{C}$ for 10 minutes followed by a ramp from $30^{\circ} \mathrm{C}$ to $300{ }^{\circ} \mathrm{C}$ at $10^{\circ} \mathrm{C} / \mathrm{min}$.

42. A thorough literature search revealed that there is dearth of methods for the preparation of symmetrical diarylamines as only three relevant papers were found on this topic: (a) K. Taniguchi, X. Jin, K. Yamaguchi, K. Nozaki, N. Mizuno, Chem. Sci. 2017, 8, 2131-2142; (b) A. Tlili, F. Monnier, M. Taillefer, Chem. Commun. 2012, 48, 6408-6410 and (c) A. V. Aksenov, N. A. Aksenov, N. A. Orazova, D. A. Aksenov, M. V. Dmitriev, M. Rubin, RSC Adv. 2015, 5, 84849-84855. In contrast, the preparation of unsymmetrical diarylamines is the subject of hundreds of papers.

43. Narasaka, K.; Kitamura, M., Eur. J. Org. Chem. 2005, 4505-4519.

44. Kitamura, M.; Suga, T.; Chiba, S.; Narasaka, K., Org. Lett. 2004, 6, 4619-4621.

45. To the best of our knowledge, no DFT calculations have been published on the double addition of nucleophiles onto the nitrogen atom of O-activated oximes.

46. Sweeney, J., Eur. J. Org. Chem. 2009, 4911-4919.

47. Rios, R.; Cordova, A., C-N bond formation: aziridine formation. In Comprehensive Chirality, Carreira, E. M.; Yamamoto, H., Eds. Elsevier B.V.: Amsterdam, Oxford \& Waltham, MA, 2012; Vol. 6, pp 399-413.

48. Liegault, B.; Lee, D.; Huestis, M. P.; Stuart, D. R.; Fagnou, K., J. Org. Chem. 2008, 73, 5022-5028.

49. Industrial approaches for the synthesis of diclofenac invariably begin with a high-temperature, copper- or palladium-catalyzed C-N cross coupling between 2,6-dichloroaniline and bromobenzene. After the diarylamine core is obtained, it takes 3-4 additional steps to arrive at the target (see Engel, J.; Kleemann, A.; Kutschner, B.; Reichert, D. Diclofenac. In Pharmaceutical Substances, Syntheses, Patents and Applications of the most relevant APIs., Georg Thieme Verlag: 2009; p 396.) In contrast, our approach to the diarylamine skeleton of diclofenac proceeds in the absence of transition metal catalysis at low temperature. 


\section{Insert Table of Contents artwork here}

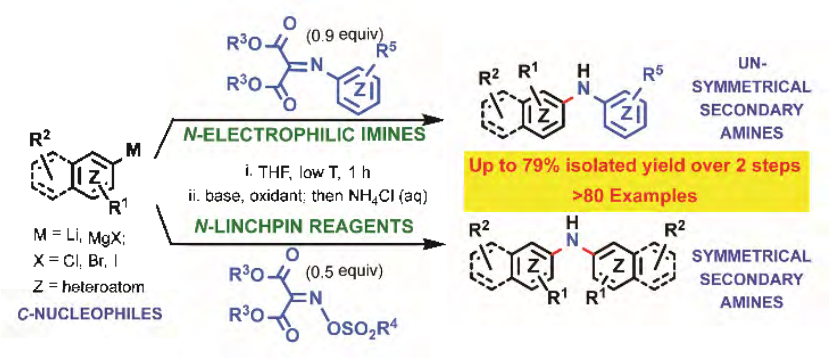

